\title{
PREDICTORS OF POST OPERATIVE BLEEDING AND BLOOD TRANS- FUSION IN CARDIAC SURGERY
}

\author{
M. TETTEY, E. ANITEYE, L. SEREBOE, F. EDWIN, D. KOTEI, M. TAMATEY, K ENTSUA- \\ MENSAH, V. AMUZU, K. FRIMPONG-BOATENG \\ National Cardiothoracic Centre, Korle Bu Teaching Hospital, \\ P. O. Box 77, Korle Bu. Accra
}

Author for Correspondence: Dr. Mark Tettey

E-Mail: mawut@mail.com

Conflict of interest: None declared

\section{SUMMARY}

Introduction: In spite of the recent advances in heart surgery, patients undergoing cardiac surgery with cardiopulmonary bypass are at risk of developing significant post-operative bleeding and substantial blood requirements.

Objective: To evaluate the impact of some perioperative predictors of post-operative bleeding, and blood transfusion after heart surgery and offer suggestions on preventive measures.

Design and Methods: A prospective analytical study. The perioperative factors studied were haemoglobin level, international normalised ratio (INR), platelet count, and total bypass time. Eighty-seven consecutive patients who underwent heart surgery in the year 2004 were selected. Each patient had laboratory work up which included full blood count, clotting profile, kidney and liver function tests. The total blood loss within the first twenty-four hours and the total units of blood transfused before the patient was discharged were also recorded.

Results: Pre-operative haemoglobin was significant in determining the total units of blood received by a patient. Increasing total bypass time caused a significant increase in the percentage reduction of the pre-operative platelet count ( $p$ $<0.004)$. However even though there was an increasing trend of post-operative bleeding with increase in total bypass time, this was not significant from the analysis $(p<0.069)$. The percentage reduction in platelet count and immediate postoperative platelet count were significant predictors of postoperative bleeding $(p<0.009)$ and $(p<0.003)$ respectively.

Conclusion: Pre-operative haemoglobin, percentage reduction in the platelet count after cardiopulmonary bypass and immediate postoperative platelet count are significant predictors of postoperative bleeding and blood requirements.
Keywords: Cardiopulmonary bypass, total bypass time, platelet count, haemoglobin, blood transfusion, post operative bleeding.

\section{INTRODUCTION}

Post-operative bleeding remains a major problem after cardiopulmonary bypass. The increased bleeding tendency after cardiopulmonary bypass is a complex reflection of multiple haemostatic defects including coagulation factor deficiency, inadequate reversal of heparinization, increased fibrinolytic activity and platelet deficiency in quantity and quality. ${ }^{1}$ The multiple factors associated with post-operative bleeding after cardiopulmonary bypass surgery makes a universal preventive protocol difficult and this is compounded by cardiopulmonary bypass induced coagulation abnormalities. $^{2}$

Blood transfusion is a life-saving intervention, which may be used preoperatively, intraoperatively, or post-operatively to manage anaemia or replace surgical blood loss. However as with other treatment options, blood transfusion may result in acute or delayed complications including the risk of transmission of infection. Even with the highest standards of donor selection, blood collection, screening, processing and storage, there remains a risk of transfusion-transmitted infection and other adverse effects. ${ }^{3}$

Blood use in cardiac surgery is closely related to preoperative haemoglobin, preoperative platelet count, total bypass time and postoperative platelet count. These can be controlled to minimize or prevent transfusion-associated complications. The knowledge of these factors is important in the control of postoperative bleeding and blood transfusion. 
The purpose of this study was to determine the significance of these peri-operative predictors of post-operative bleeding and blood usage in patients undergoing heart surgery and offer suggestions to minimise the increasing usage of blood.

\section{PATIENTS AND METHODS}

Eighty-seven consecutive patients who underwent open heart surgery at the National Cardiothoracic Centre from 1st January to 31st December 2004 were included in this prospective study. All the patients had pre-operative full blood count (FBC), partial thromboplastin time (PTT), INR, urea, electrolytes, creatinine and liver function tests. These tests were repeated immediately patients were admitted in the Intensive Care Unit from theatre. The total bypass time for each patient was recorded.

Induction of anaesthesia was by midazolam $0.6 \mathrm{mg} / \mathrm{kg}$, fentanyl $3 \mathrm{ug} / \mathrm{kg}$, pancuronium $0.1 \mathrm{mg} / \mathrm{kg}$. Pre-bypass anaesthesia was maintained by nitrous-oxide/oxygen isoflurane and a propofol infusion $(12 \mathrm{mg} / \mathrm{kg} / \mathrm{hr})$. On bypass, anaesthesia was maintained by total intravenous infusion using propofol (8-12 mg/kg/hour) and fentanyl boluses.

The bypass circuit was constructed with a membrane oxygenator, cardiotomy reservoir, phosphorylated inner tube lining and other accessories from Dideco Perfusion Tubing Systems, D 905 and D 902 Lilliput 2 (Sorin Group, Mirandola, Italy). Anticoagulation was achieved using unfractionated heparin at a dose of $300 \mathrm{IU} / \mathrm{kg}$ of body weight to increase the whole blood activated clotting time (ACT) above 400 seconds. Hemochron 401 SN - T10565-4(ITC, New Jersey, USA) was used in measuring the ACT. The mean arterial blood pressure was maintained between 50 and $70 \mathrm{mmHg}$. Myocardial protection was achieved by using cold crystalloid anterograde cardioplegia. An equivalent dose of protamine $3 \mathrm{mg} / \mathrm{kg}$ of body weight was given to the patients after patients were weaned off the cardiopulmonary bypass machine. Patients were weaned off the bypass machine only when they were normothermic. The ACT was again checked after the protamine to ensure complete reversal of the heparin. The $\mathrm{pH}$ of the arterial blood after surgery was kept within normal limits by the administration of $8.4 \%$ sodium bicarbonate solution. The partial pressure of oxygen in arterial blood was also kept in excess of $150 \mathrm{mmHg}$ using an inspired oxygen concentration of 40-50\%.

Heparin was reversed with protamine after coming off bypass and tranexamic acid was administered immediately after surgery in all patients. The total mediastinal bleeding was determined through the sum of the losses from the thoracic drains starting after the closure of the sternum for a period of 24 hours. The decision to transfuse any patient was determined by the surgical and the anaesthetic teams. This was based on immediate postoperative haemoglobin level. None of the patients was on any anticoagulant preoperatively.

\section{Data Analysis}

Data was captured using Excel. Analysis was done using Statistical Package for Social Sciences (SPSS) version 11.0.0 for windows (SPSS Inc., Chicago, IL, USA). A $p$-value of less than 0.05 was considered significant. Continuous variables were summarized using means and standard deviation while categorical data were summarized using percentages. Analysis of Variance (ANOVA) was used to compare mean of categories in the data.

\section{RESULTS}

The age distributions of patients are displayed in Table 1. Of the 87 patients studied 34 were male $(39.1 \%)$ and 53 were female $(60.9 \%)$. Preoperative diagnoses of the cases included in the study are shown in Table 1. Fifty seven percent of these patients were operated for acquired heart diseases and forty three percent for congenital heart diseases. Ventricular septal defect accounted for $45.9 \%$ of the congenital heart diseases.

Two out of the 87 patients included in this study were re-operated for life threatening post-operative bleeding. In both cases generalised oozing was found at re-exploration. Meticulous coagulation was carried out and this reduced the post-operative bleeding considerably.

The quantity of blood transfused per patient was studied. Six $(6.9 \%)$ had no blood transfusion, 35 (40.2\%) 1 unit, 24 (27.6\%) 2 units, 11 (12.6\%) 3 units, $9(10.3 \%) 4$ units and $2(2.4 \%)>4$ units. Fifty-nine $(67.8 \%)$ had only one or two units of blood transfused. The characteristics of the 6 patients who did not receive blood are shown in Table 2 .

Two of the patients who were Jehovah's Witnesses were given pre-operative erythropoietin therapy to increase their preoperative haemoglobin level. None of the patients received blood transfusion before surgery. 
Table 1 Age distribution, indication for surgery

\begin{tabular}{|c|c|c|c|c|c|c|c|c|}
\hline & \multicolumn{7}{|c|}{ Indications for surgery } & MVD \\
\cline { 2 - 9 } Age & CHD & MVD & AVD & $\begin{array}{c}\text { MVD } \\
\text { AVD }\end{array}$ & $\begin{array}{c}\text { MVD/AVD } \\
\text { TVD }\end{array}$ & CAD & Total (\%) \\
\hline $0-10$ & 20 & - & - & - & 1 & - & - & $21(24.1)$ \\
\hline $11-20$ & 6 & 3 & 1 & - & 7 & - & - & $17(19.5)$ \\
\hline $21-30$ & 8 & 7 & - & 1 & - & - & - & $16(18.4)$ \\
\hline $31-40$ & 1 & 2 & - & 4 & - & - & - & $7(8.0)$ \\
\hline $41-50$ & 2 & 4 & 2 & 4 & 1 & - & 2 & $15(17.3)$ \\
\hline $51-60$ & - & 4 & 1 & 2 & - & - & 1 & $8(9.2)$ \\
\hline $61-70$ & - & - & 2 & - & - & 1 & - & $3(3.5)$ \\
\hline Total $(\%)$ & $37(42.6)$ & $20(22.9)$ & $6(6.9)$ & $11(12.6)$ & $9(10.4)$ & $1(1.1)$ & $3(3.5)$ & $87(100)$ \\
\hline
\end{tabular}

CHD (Congenital heart disease), MVD (Mitral valve disease), AVD (Aortic valve disease), TVD (Tricuspid valve disease), CAD (Coronary artery disease)

Table 2 Characteristics of patients who received no blood transfusion.

\begin{tabular}{|l|l|l|l|l|l|l|l|l|}
\hline $\begin{array}{l}\text { Age } \\
(\mathrm{yrs})\end{array}$ & Sex & Diagnosis & $\begin{array}{l}\text { Pre } \\
\text {-operative } \\
\text { haemoglobin } \\
(\mathrm{g} / \mathrm{dl})\end{array}$ & $\begin{array}{l}\text { Pre } \\
\text {-operative } \\
\text { Platelet } \\
\text { Count } \\
\left(\mathrm{x} 10^{9} / \mathrm{L}\right)\end{array}$ & $\begin{array}{l}\text { Post } \\
\text { Operative } \\
\text { Platelet } \\
\text { Count } \\
\left(\mathrm{x} 10^{9} / \mathrm{L}\right)\end{array}$ & $\begin{array}{l}\text { Total } \\
\text { Bypass } \\
\text { Time } \\
(\mathrm{mins})\end{array}$ & $\begin{array}{l}\text { Post } \\
\text { Operative } \\
\text { Bleeding } \\
(\mathrm{ml} / \mathrm{kg})\end{array}$ & $\begin{array}{l}\text { Erythro } \\
\text { poietin } \\
\text { use }\end{array}$ \\
\hline 27 & $\mathrm{~F}$ & VSD & 14.9 & 198 & 102 & 95 & 10 & YES \\
\hline 36 & $\mathrm{M}$ & MVD & 15.6 & 190 & 123 & 103 & 16.6 & NIL \\
\hline 48 & $\mathrm{~F}$ & MVD & 13.9 & 218 & 100 & 60 & 6.7 & YES \\
\hline 22 & $\mathrm{M}$ & MVD & 15.5 & 179 & 111 & 100 & 5.5 & NIL \\
\hline 56 & F & MVD & 15.8 & 200 & 111 & 115 & 9.3 & NIL \\
\hline 31 & M & MVD/AVD & 15.8 & 357 & 203 & 153 & 10.2 & NIL \\
\hline
\end{tabular}

The result of pre-operative haemoglobin level and the average units of blood transfused is shown in Table 3. Lower haemoglobin levels were associated with increased blood transfusion. Postoperative platelet count from this study is significant in determining postoperative bleeding.

Table 3 Pre-operative haemoglobin level and mean number of blood units transfused

\begin{tabular}{|l|c|c|}
\hline $\begin{array}{l}\text { Haemoglobin } \\
\text { range } \\
(\mathrm{g} / \mathrm{dl})\end{array}$ & $\begin{array}{c}\text { Mean blood } \\
\text { Transfused } \\
(\text { Units })\end{array}$ & Number \\
\hline$<10$ & 4.00 & 1 \\
\hline $10.0-11.0$ & $3.50 \pm 2.12^{*}$ & 2 \\
\hline $11.1-12.0$ & $2.57 \pm 1.27$ & 7 \\
\hline $12.1-13.0$ & $1.50 \pm 1.27$ & 10 \\
\hline $13.1-14.0$ & $1.80 \pm 1.48$ & 5 \\
\hline$>14$ & $1.87 \pm 2.18$ & 23 \\
\hline Total & $2.00 \pm 1.82$ & 48 \\
\hline
\end{tabular}

*Mean \pm Standard deviation

Using Analysis of Variance (ANOVA), significant postoperative bleeding occurred when platelet count was $100 \times 10^{9} / 1$ and below $(p<.003)$ shown in Figure 1. Percentage reduction in platelet count above $50 \%$ accounted for significant bleeding ( $p<$ $.007)$. This is shown in Figure 2.

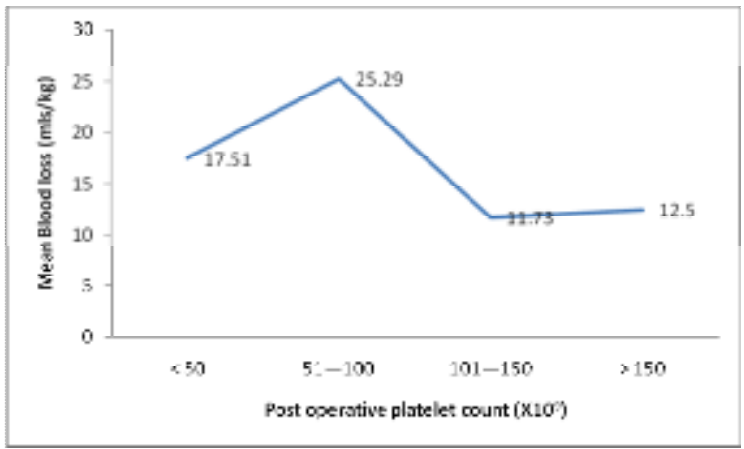

Figure 1 Immediate postoperative platelet count and mean blood loss in patients. 


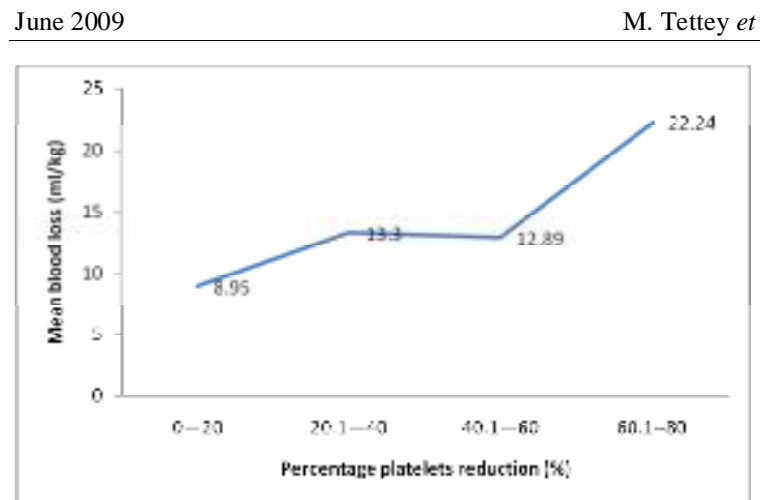

Figure 2 Percentage platelet reduction and mean blood loss in patients.

The result of the evaluation of the effect of the total bypass time on the percentage reduction in platelet count immediately after operation is shown in Figure 3. Pearson chi-square test showed significant correlation between total bypass time and percentage reduction in platelet count. $(p<$ 030). The total bypass time and the total postoperative blood loss in 24 hours were also evaluated. When the total bypass time was less than 61 minutes, the mean blood loss was $10.27 \mathrm{mls} / \mathrm{kg} / 24$ hours, from 61 to 120 minutes the mean blood loss was $13.30 \mathrm{mls} / \mathrm{kg} / 24 \mathrm{hrs}$ and above 120 minutes, the mean blood loss was $17.25 \mathrm{mls} / \mathrm{kg} / 24$ hours. Using Analysis of Variance (ANOVA), the data however showed statistical insignificance $p<0.069$.

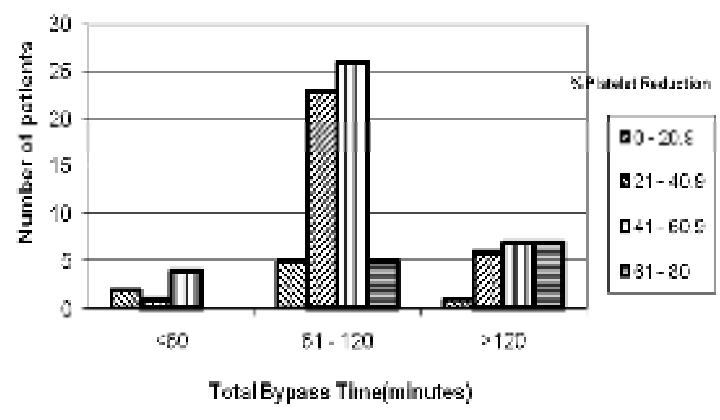

Figure 3 Total bypass time and percentage reduction in platelet count after heart operation.

\section{DISCUSSION}

The three main factors that prevent excessive bleeding are blood vessel constriction, platelet activation and the activity of clotting factors that circulate in the blood. Abnormalities in these natural compensatory mechanisms may lead to potentially dangerous bleeding. ${ }^{4}$ Perioperative bleeding is linked to surgical injury of blood vessels and defects of the haemostatic mechanisms. In heart surgery, the tendency to excessive bleeding is due to the surgical procedure itself involving major vascular structures and the deleterious effect of the extracorporeal circulation on the haemostatic mechanisms. ${ }^{5}$ The incidence of life threatening bleeding after open-heart surgery is between 5 to $25 \%$ according to some studies. ${ }^{5}$ The present study shows that 2 out of the $87(2.3 \%)$ patients operated upon needed re-exploration for lifethreatening postoperative bleeding. Similar results have been reported by other workers.,

Pawan et al in a previous study found that patient's with INR less than 2 had less bleeding post operatively. ${ }^{7}$ In the present study none of the patients had an INR of more than 1.4. The incidence of having an abnormal PT in a pre-operative group is low and is reported to be between 0 to $3 \%$ which is similar to our findings. ${ }^{7}$

Several studies have been carried out to determine the impact of hematocrit and other perioperative predictors of transfusion requirements in cardiac surgery. Hematocrit $<35 \%$ has been found to be one of the strongest predictors of blood transfusion. ${ }^{8,9,10}$ Pre-operative haemoglobin has been shown in our study to correlate with the mean number of units of blood transfused. The higher the pre-operative haemoglobin the lower the number of units of blood transfused. An important finding was the low blood transfusion requirements observed in patients who with very good preoperative haemoglobin levels. However patients who had low preoperative haemoglobin level needed more blood transfusion and this was evident in the study especially in the patients who needed 4 or more units of blood. Acute normovolaemic hemodilution was used in adult patients with haemoglobin levels above $14.5 \mathrm{~g} / \mathrm{dl}$ and one or two units of blood were harvested before the commencement of cardiopulmonary bypass. Good nutrition and the use of drugs- erythropoietin, haematinics and antimalarials can help increase the level of haemoglobin pre-operatively. ${ }^{11}$

It was also found that significant bleeding occurred when platelet count was below $100 \times 10^{9} / 1$. Post-operative percentage reduction in platelet count above 60 has also been shown in our analysis to result in significant postoperative blood loss. It is important to note that even though the immediate post operative platelet count may be above $100 \times 10^{9} / 1$, the acute reduction coupled with an 
acquired platelet dysfunction is enough to precipitate significant postoperative bleeding. Other studies have also demonstrated the significance of low postoperative platelet count as one of the major

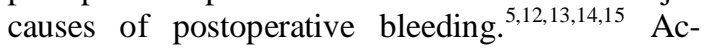
quired platelet dysfunction as a cause of postoperative bleeding after cardiopulmonary bypass surgery, is amplified by the extracorporeal circuit itself, hypothermia, heparin and other drugs. ${ }^{6}$ The drop in platelet count initially may be attributed to the haemodilution by the non-blood priming solution, platelet adhesion to the circuit surfaces, platelet aggregation and activation and removal of damaged platelet by the reticulo-endothelial system. ${ }^{5,6}$

Prolonged cardiopulmonary bypass time greater than 120 minutes was associated with significant percentage reduction in platelet count as compared with the total bypass time of less than 60 minutes. This finding from the current study among Africans is significant since other studies did not show any correlation between the decrease in platelet count and total bypass time. ${ }^{16,17}$ Genetic analysis in previous scientific studies have revealed that seven polymorphisms of platelet surface receptors, coagulation proteins and angiotensin converting enzyme demonstrated a significant association with increased bleeding after heart surgery. These genetic factors are independent of the clinical characteristics used to predict bleeding and appear to explain at least as much of the variation seen among patients. ${ }^{4,18}$ The possibility of genetic variations affecting the function of platelets after bypass surgery in Africans need more research.

Cardiopulmonary bypass is considered one of the most important factors for bleeding associated with postoperative bleeding and the use of blood products as shown by previous studies. ${ }^{2,5,8,19,20}$ Our study shows a similar correlation between the total bypass time and postoperative bleeding but this was not statistically significant. Of the 11 patients who received more than 4 units of blood, $8(73 \%)$ were females and this confirmed the finding in a previous study in which females received more blood than males. ${ }^{8}$ More than $50 \%$ of these patients had haemoglobin levels less than $13 \mathrm{~g} / \mathrm{dl}$ and immediate postoperative platelet counts less than $100 \times 10^{9} / 1$. The total bypass time for $8(73 \%)$ of the patient was more than 120 minutes and 9 $(82 \%)$ had significant postoperative bleeding (> $10 \mathrm{ml} / \mathrm{kg} / 24$ hours). Exposure of heparinised blood to the wound and to the synthetic surfaces of the extracorporeal perfusion circuit stimulates thrombosis and partially activates coagulation proteins, fibrinolytic proteins, platelets, and blood cells compromising wound haemostasis. ${ }^{5}$

\section{CONCLUSION}

The preoperative haemoglobin level is an important predictor of blood transfusion in heart surgery. Post operative platelet count and percentage reduction in platelet count are also significant predictors of post operative bleeding. Improving on the preoperative haemoglobin levels, reducing cardiopulmonary bypass time and using drugs that can preserve platelet function can help reduce postoperative bleeding and blood use in cardiac surgery.

\section{REFERENCES}

1. Yamada T. et al. Comprehensive haemostasis analysis during cardiopulmonary bypass with Sonoclot analyzer and glass bead activated Heparinase Test. Anesth. Analg 2004; 98: 1134.

2. Miana L. A. et al. Risk factors of post operative bleeding after adult cardiac surgery. Braz. J. Cardiovas Surg Vol.19 no.3 Jul/Sept. 2004.

3. The clinical use of blood in Medicine, Obstetrics, Paediatrics, Surgery and Anaesthesia, Trauma and Burns. WHO/BTS/99.2 Chapter 7,pg 127.

4. Ian Welsby. Specific variants of genes predict bleeding after heart surgery. Medical Research News, 4-May-2005. www.newsmedical.net/?id=9787.

5. Andre L. Tyszka. Methods and techniques to reduce the use of blood components. www.perfline.com/textbook/local/aprotinin.ht $\mathrm{ml}$.

6. Glenn's Thoracic and Cardiovascular Surgery 5th Edition, Prentice-Hall International Inc. 1991: 1550-1551

7. Pawan K. Preoperative International Normalised Ratio and bleeding during open heart procedure. Ind. J Thorac Cardiovasc Surg 2004; 20: 132-134.

8. Bharathi H. et al. Blood use in patients undergoing coronary artery bypass surgery: Impact of cardiopulmonary bypass pump, hematocrit,gender, age, and body weight. Anesth Analg 2003;97:958-963.

9. Jean-Francois H. et al. Transfusions in patients undergoing cardiac surgery with autologous blood. Can J Anesth 2000; 47:705-711.

10. Moskowitz D. et al. Predictors of transfusion requirements for cardiac surgical procedures at a blood conservation center. Ann Thorac Surg 2004; 77:626-634. 
11. Frimpong-Boateng K. et al. Cardiopulmonary bypass in Jehovah's Witnesses. W Afr J Med 2003; 22:92-94.

12. Belcher R. et al. Post operative bleeding after coronary artery bypass surgery with cardiopulmonary bypass. Anesth Analg 2002; 95(5):1466.

13. 13. Bagge L. et al. Coagulation, fibrinolysis and bleeding after open heart surgery. Scand J Thorac Cardivasc Surg 1986; 20(2):151-60.

14. Kunitomo R. et al. Predictive factors for platelet number after cardiopulmonary bypass and postoperative blood loss. ASAIO Journal 2002;48(6):671-674.

15. Suzuki Y. et al. Intergrilin prevents prolonged bleeding times after cardiopulmonary bypass. Ann Thorac Surg 1998 Aug;66(2):373-81.

16. McKenna R. et al. The hemostatic mechanism after open-heart surgery. II. Frequency of ab- normal platelet functions during and after extracorporeal circulation. J Thorac Cardiovasc Surg 1975 Aug;70(2):298-308.

17. Sabiston and Spencer. Surgery of the Chest. Fifth Edition, W. B. Saunders Company Philadelphia. 1990: 1116.

18. Durham N. C. Gene variants predict bleeding after heart surgery.

www.sciencedaily.com/releases/2005/05/0505 04104229.htm.

19. Ram Kakaiya. Cardiopulmonary bypass surgery in idiopathic thrombocytopenic purpura. The Institute For Transfusion Medicine 2004 Issue no. 2.

www.itxm.org/TMU2004/Issue2004-2.htm.

20. Tripti C. Kataria. et al. Long cardiopulmonary time predicts postoperative bleeding despite strict utility of transfusion algorithms. Anesthesiology 2002;96 A129. 